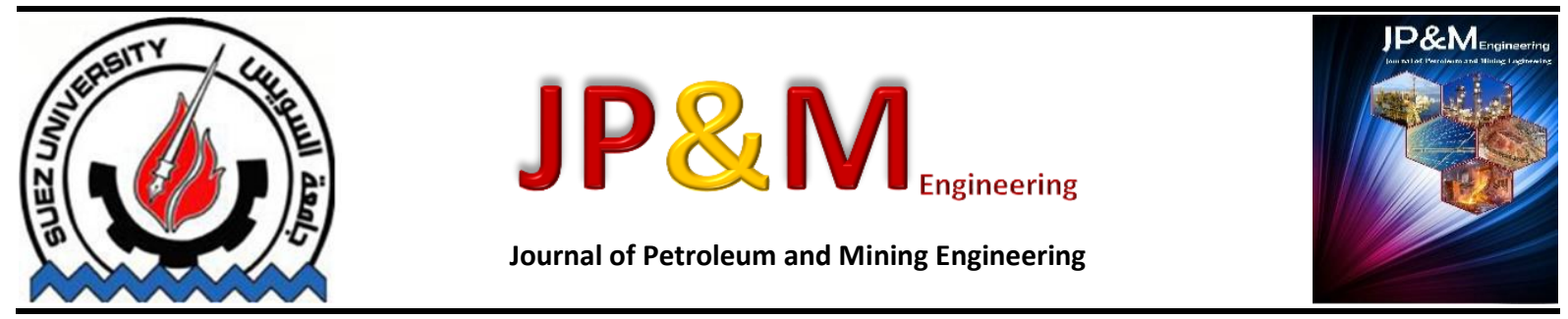

\title{
Production and Characterization of AA7075-Graphite Composite Using Friction Stir Processing
}

\author{
Osama M. Awad ${ }^{\mathrm{a}}$, Mohamed M. El-Sayed Seleman ${ }^{\mathrm{b}, \mathrm{c}}$, M. M. Z. Ahmed ${ }^{\mathrm{b}, \mathrm{c}, \mathrm{d}}$, H. R. Ammar ${ }^{\mathrm{b}, \mathrm{c}}$
}

aNasr Petroleum Company, Suez, Egypt

${ }^{b}$ Department of Metallurgical and Materials Engineering, Faculty of Petroleum and Mining Engineering, Suez University, 43511, Suez, Egypt 'Suez and Sinai Metallurgical and Materials Research Center of Scientific Excellence (SSMMR-CSE), 43511 Suez, Egypt ${ }^{\mathrm{d}}$ The British University in Egypt, Mechanical Engineering Department, El-Sherouk City 11837, Cairo, Egypt *Corresponding author: eng.osama_awad@yahoo.com

\section{Keywords}

AA7075 Al alloy/graphite composite, Friction Stir Processing,Microstructure , Mechanical Properties.

\begin{abstract}
AA 7075 Aluminum alloy has been received a special attention in aerospace and transportation industries because it provides a good combination of strength, ductility, and toughness. In this study, friction stir processing (FSP) technique is used to produce a self-lubricating AA7075/graphite composite. The composite was produced at different rotating speeds of 400,800 , and $1200 \mathrm{rpm}$ with a constant traveling speed of $50 \mathrm{~mm} / \mathrm{min}$ and $3^{\circ}$ tilt angle applied for one and two passes for each condition. Optical microscopy (OM), and scanning electron microscopy (SEM) were used to investigate microstructure. Vickers hardness and wear testing were conducted to the composite specimens. It was obtained that the dispersion of graphite particles in the AA7075 Al alloy enhanced by increasing both rotating speed and number of passes. The produced AA7075/graphite composite showed higher hardness and wear resistance than the AA7075 base alloy. The highest hardness value $(156.2 \mathrm{Hv})$ was gained for the produced AA7075/graphite composite at $800 \mathrm{rpm}$ rotating speed after FSP second pass comparing to base metal $(79 \mathrm{Hv})$. Whereas, the higher wear resistance value was obtained for the processed composite at $800 \mathrm{rpm}$ after the FSP first pass.
\end{abstract}

\section{Introduction}

The 7XXX series of Al alloys provide the highest strength among all aluminum alloys. These alloys offer a wide range of strength and ductility. They have been extensively used in aerospace and other structural applications and also for the development of Metal Matrix Composites (MMCs). Metal matrix composites usually consist of light-weight metals like aluminum, magnesium, or titanium, and the reinforcements are usually ceramic particulates, whiskers, or fibers. The reinforcements are an important factor in determining the properties and the performance of the MMCs [1, 2].

Friction stir processing has been used to fabricate various types of aluminum composite materials. SiC particle reinforced aluminum alloys have been studied the most [3-5]. For example, the feasibility of making bulk SiCp reinforced aluminum via friction stir processing (FSP) was demonstrated by Wang et al. [6]. Good interface bonding between particles and the base metal could be obtained. The volume fraction of $\mathrm{SiCp}$ is about $1.5 \%$ in the reinforced region. The microhardness of the reinforced composite is $10 \%$ higher than that of the base material, Al-6Mg-Mn alloy.

Alumina particle reinforced aluminum alloys via friction stir processing has also been studied $[7,8]$. Shafiei-Zarghani et al. [7] used FSP to incorporate nano-sized $\mathrm{Al}_{2} \mathrm{O}_{3}$ into $\mathrm{AA6082} \mathrm{Al}$ alloy to form composite surface layer. The results showed that the increasing in number of FSP passes causes more uniform distribution of nano-sized alumina particles. Hardness of the surface improved three times as compared to that of the Al alloy. The wear rate is reduced to one third of that of the as-received Al alloy [7].

Similar to SiC reinforced aluminum composites, the stirring of the FSP tool has a substantial influence on the distribution of alumina particles in $\mathrm{Al}_{2} \mathrm{O}_{3} / \mathrm{Al}$ composites [9]. The stirring of the tool can also change 
the shape of the reinforcement particles. It breaks off the sharp edges of the bigger particles, rounding them up at the same time. This action results in smaller, round particles in the nugget. [8].

Surekha et al. [10] investigated the effect of processing parameters on the corrosion behavior of friction stir processed high strength precipitation hardened AA2219-T87 alloy. The study showed an improved corrosion resistance for the processed alloy with the number of passes.

Aluminum alloy 7075 , the most common alloy of this series, provides a good combination of strength, ductility, and toughness [11]. However aluminum alloys have limited tribological applications due to their low wear resistance under lubricating conditions.

Graphite is very effective in reducing the wear and friction coefficient of the composites, because graphite particles acting as solid lubricant between the sliding surfaces and inhibiting metal to metal contact. These self-lubricating composites have low thermal expansion, low friction and wear, and reduced temperature rise at the wearing contact surface [12]. Previously, various methods have been used to fabricate these composites such as centrifugal casting and powder metallurgy. Agglomeration of graphite particles and residual porosity are the most important problems of these methods. FSP was employed to produce these composites due to simultaneous stirring of materials during the FSP which can solve the graphite particles agglomeration [13].

The current study aims to fabricate AA7075/graphite composite based on a friction stir processing technique. The effect of the process parameters on the microstructures and mechanical properties in terms of hardness and wear resistance were discussed.

\section{Experimental Work}

\section{Materials}

Rolled aluminum alloy (AA7075) plates of (150 $\mathrm{mm}$ length, $75 \mathrm{~mm}$ width, and $5 \mathrm{~mm}$ thickness) were used as a substrate. The chemical composition and mechanical properties of the AA7075 (as received) used is summarized in Table 1, 2. Graphite powder of less than $40 \mu \mathrm{m}$ particle size was used as reinforcement particulates.

Table 1 Chemical composition of AA7075 (in Wt.\%)

\begin{tabular}{ccccccccc}
\hline $\mathrm{Si}$ & $\mathrm{Fe}$ & $\mathrm{Cu}$ & $\mathrm{Mn}$ & $\begin{array}{c}\mathrm{M} \\
\mathrm{g}\end{array}$ & $\mathrm{Cr}$ & $\mathrm{Zn}$ & $\mathrm{Ti}$ & $\mathrm{Al}$ \\
\hline $\begin{array}{c}0.07 \\
4\end{array}$ & $\begin{array}{c}0.21 \\
6\end{array}$ & $\begin{array}{c}1.9 \\
4\end{array}$ & $\begin{array}{c}0.05 \\
1\end{array}$ & 2.66 & $\begin{array}{c}0.21 \\
1\end{array}$ & $\begin{array}{c}5.9 \\
7\end{array}$ & $\begin{array}{c}0.01 \\
2\end{array}$ & $\begin{array}{c}\text { Bal } \\
\cdot\end{array}$ \\
\hline
\end{tabular}

Table 2 Mechanical properties of AA7075

\begin{tabular}{ll}
\hline Ultimate tensile strength $(\mathrm{MPa})$ & $525.47 \pm 0.4$ \\
\hline Elongation $(\%)$ & $11.2 \pm 0.2$ \\
\hline Vickers hardness $(\mathrm{Hv})$ & $170 \pm 5$ \\
\hline
\end{tabular}

In order to release internal stresses and to ensure that the enhancement in the microstructure and the mechanical properties are resulted from the FSP only, the received AA7075-T651 plates were fully annealed to AA7075-O [14]. Annealing was conducted by heating plates up to $470^{\circ} \mathrm{C}$, soaking them at this temperature for $3 \mathrm{~h}$, and then furnace cooled [15].

FSP tool (H13) with a cylindrical pin profile of ( 5 $\mathrm{mm}$ pin diameter, $3 \mathrm{~mm}$ pin depth, and $17 \mathrm{~mm}$ shoulder diameter) was used to disperse the graphite in the alloy matrix as shown in Fig.1.

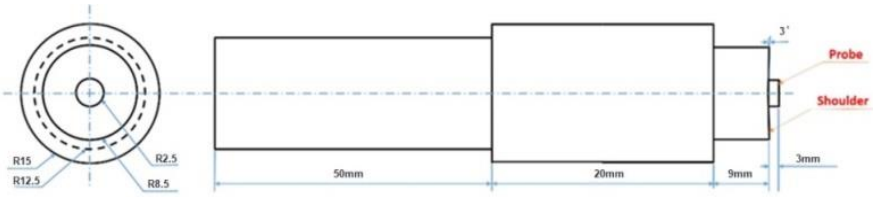

Fig. 1 Schematic drawing for FSP tool

\section{Fabrication of AA7075/graphite composites}

Firstly, a groove of $1 \mathrm{~mm}$ in width and $3 \mathrm{~mm}$ in depth was machined along the length of all the AA7075 plates, and then graphite powder was added into the grooves until grooves completely filled. After that, the groove was closed using a pin less FSP tool, and finally conducting FSP using a cylindrical pin profile tool. Various friction stir processing parameters used to fabricate the required AA7075/graphite composite (AA7075/Graphite as shown in Table 3.

Table 3 illustrates the used FSP parameters

\begin{tabular}{cc}
\hline Rotating speed & $400 / 800 / 1200 \mathrm{rpm}$ \\
\hline Number of passes & 1st pass $/ 2 \mathrm{nd}$ pass \\
\hline Travel speed & $50 \mathrm{~mm} / \mathrm{min}$ \\
\hline Tool tilt angle & 3 degree \\
\hline
\end{tabular}

In order to study the effect of addition of graphite powder in the AA7075 Al alloy matrix, another samples only FSPed (without powder) at the same condition. Table 4, shows the produced samples code number and the FSP parameters.

Table 4 Samples no. at different FSP parameters

\begin{tabular}{cccc}
\hline $\begin{array}{c}\text { Sample No. } \\
\text { (With } \\
\text { powder) }\end{array}$ & $\begin{array}{c}\text { Sample No. } \\
\text { (Without } \\
\text { powder) }\end{array}$ & $\begin{array}{c}\text { Rotating } \\
\text { speed } \\
(\mathrm{rpm})\end{array}$ & $\begin{array}{c}\text { Number of } \\
\text { FSP passes }\end{array}$ \\
\hline S1 & S7 & 400 & $1^{\text {st }}$ pass \\
S2 & S8 & 400 & $2^{\text {nd }}$ pass \\
S3 & S9 & 800 & $1^{\text {st }}$ pass \\
S4 & S10 & 800 & $2^{\text {nd }}$ pass \\
S5 & S11 & 1200 & $1^{\text {st }}$ pass \\
S6 & S12 & 1200 & $2^{\text {nd }}$ pass \\
\hline
\end{tabular}




\section{Metallographic examination}

The metallographic examination was conducted using both optical and scanning electron microscopy for the AA7075-O base material, cross-sections of the processed base alloy, and the produced AA7075/graphite composite.

\section{Mechanical properties evaluation}

\section{Hardness measurements}

Average hardness values were measured at the stir zone (nugget) for all FSP produced samples on the cross-section transverse to the processing direction using Vickers hardness tester. The test was conducted on three measurements lines at a depth of $1.5 \mathrm{~mm}$ from surface for the first line, $2.5 \mathrm{~mm}$ depth for the second line, and $3.5 \mathrm{~mm}$ for the third line, the internal spacing between each measurement step $0.5 \mathrm{~mm}$, under a load of $1000 \mathrm{gf}$ for a $15 \mathrm{sec}$ dwell time.

Wear test

The wear behavior of the AA7075-O BM, AA7075/graphite composite, and the FSPed samples (without powder) was studied through pin-on-bush wear testing machine at room temperature and under dray condition. Wear test specimens of $5 \times 5 \mathrm{~mm}^{2}$ cross section and $15 \mathrm{~mm}$ length were cut from the base metal and from the middle of FSP stirred zone (nugget).

The sliding counter face (bush) was made of 58 HRC hard steel. The bush was fine ground by SiC paper grit 800 and cleaned before the test to remove any residuals from the previous run. The first group of AA7075-O base metal was tested at a constant running time of $10 \mathrm{~min}$ (sliding distance of $8.92 \mathrm{~km}$ ) using normal loads of $2.45,3.04,3.92$, and $6.37 \mathrm{~N}$ $(250,310,400$, and $650 \mathrm{gf})$ to explore the steady state wear behavior.

Based on the result of the first group, a constant moderate load of $3.04 \mathrm{~N}$ was chosen to test the second group of specimens under running time of 10 $\min (8.92 \mathrm{~km})$. Each wear experiment was repeated three times to ensure repeatability of results. The weight loss, wear rate, and wear resistance were calculated. In order to study the wear mechanisms, the worn surfaces of wear samples were examined by optical microscope and SEM.

\section{Results and discussions}

\section{Macro-structure examination}

Macroscopic appearances of the nugget zone in which graphite powder was dispersed by one and two FSP passes at constant travel speed of $50 \mathrm{~mm} / \mathrm{min}$ and different rotating speeds of $(400,800$, and $1200 \mathrm{rpm})$ are shown in Fig.2, Fig.3, and Fig.4 respectively.
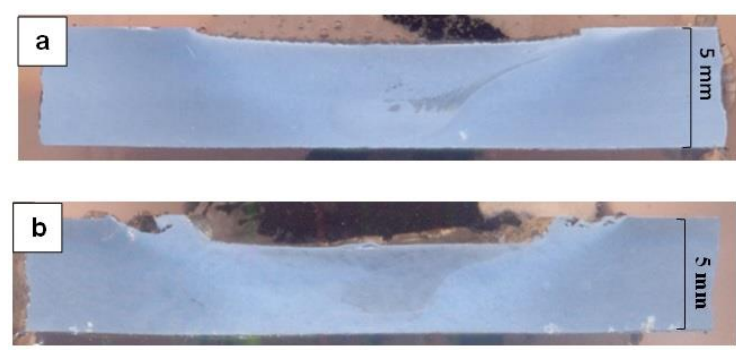

Fig.2 Optical Macrographs of AA7075/Graphite MMC produced by FSP at $400 \mathrm{rpm}$ after $1^{\text {st }}(\mathrm{a})$ and $2^{\text {nd }}$ pass (b)
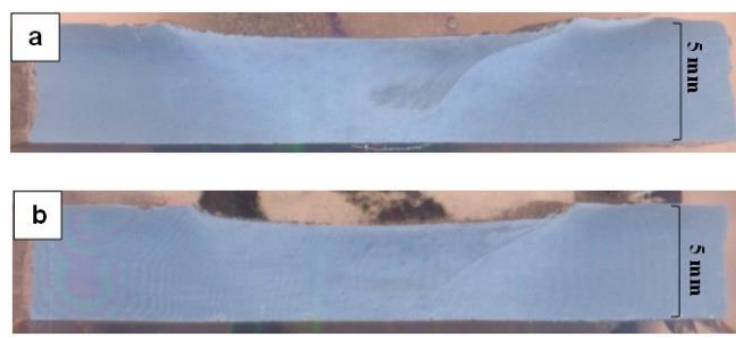

Fig. 3 Optical Macrographs of AA7075/Graphite MMC produced by FSP at $800 \mathrm{rpm}$ after $1^{\text {st }}(\mathrm{a})$ and $2^{\text {nd }}$ pass (b)
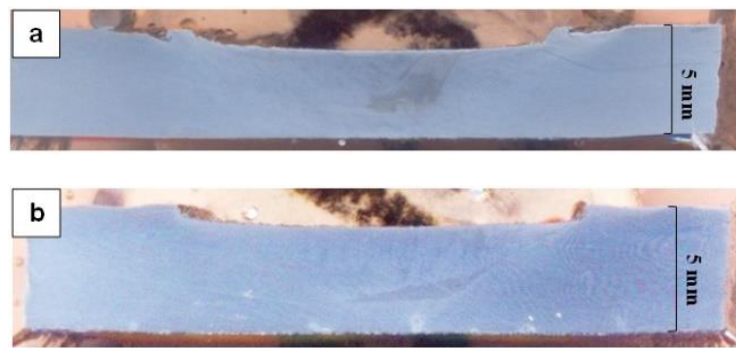

Fig. 4 Optical Macrographs of AA7075/Graphite MMC produced by FSP at $1200 \mathrm{rpm}$ after $1^{\text {st }}$ (a) and $2^{\text {nd }}$ pass (b)

As shown in Fig.2, Fig.3, and Fig.4, the agglomeration size of graphite powder is reduced by increasing the number of FSP passes. After one pass, graphite particles become entangled in AA7075 matrix as presented in Figs. 2(a), 3 (a), and 4(a). After two passes, graphite particles are dispersed more uniformly as given in Figs. 2(b), 3(b), and 4(b). The macrostructure figures show the dispersion of the graphite particles in the AA7075 matrix without FSP defects "cracks or tunnels".

\section{Microstructure examination}

The differences in microstructure between AA7075-O base metal, AA7075 FSPed (without powder), AA7075/graphite composite $1^{\text {st }}$ pass, and $2^{\text {nd }}$ pass are shown in Fig.5 (a, b, c, and d) respectively. 

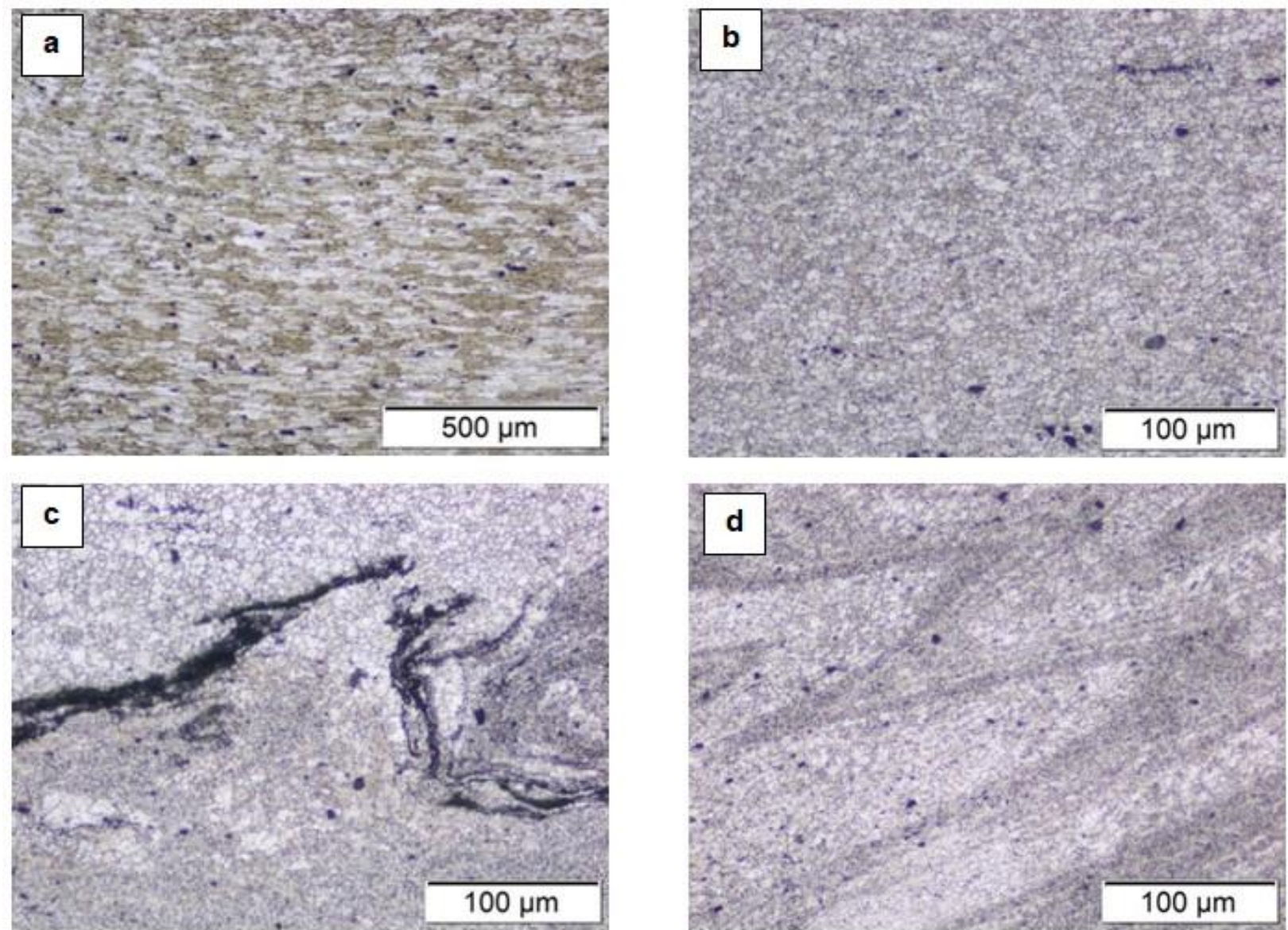

Fig. 5 Optical Microstructure of (a) AA7075-O BM, (b) AA7075 FSPed (Without powder), (c) AA7075-Graphite MMC FSPed at $800 \mathrm{rpm} 1^{\text {st }}$ pass, (d) AA7075-Graphite MMC FSPed at $800 \mathrm{rpm} 2^{\text {nd }}$ pass

The initial microstructure consisted of large elongated grains for a rolled and subsequently annealed structure, as can be seen in the Fig 5 (a). Fine and coarse strengthening precipitates with different sizes were dispersed through the matrix. Due to FSP, a microstructure of fine and equiaxed grains was reformed in the FSP nugget zone Fig 5 (b).

Graphite was clearly appeared in the microstructure of AA7075/graphite composite which produced by FSP at $800 \mathrm{rpm}$ rotational speed and 50 $\mathrm{mm} / \mathrm{min}$ transverse speed for $1^{\text {st }}$ pass Fig $5(\mathrm{C})$, and graphite agglomeration regions was observed. After the $2^{\text {nd }}$ pass of FSP, a better dispersion of graphite particles in the AA7075 metal matrix was shown Fig 5 (d). More features details in the microstructure of AA7075/graphite composite at various FSP parameters were observed in Fig.6 and Fig.7.

A microstructure evaluation was done for the AA7075/graphite composite produced by FSP at 400 , 800 , and $1200 \mathrm{rpm}$ rotating speeds to study the effect of the various FSP rotating speed on the MMC microstructure. It was observed that the composite produced at FSP of $800 \mathrm{rpm}$ rotating speed show more homogenous microstructure than the $\mathrm{MMC}$ produced at FSP of $400 \mathrm{rpm}$ rotating speed.
Also it was reported that the AA7075 matrix precipitates particle size was decreased by increasing the rotating speed. Although MMC produced at 800 rpm $1^{\text {st }}$ pass Fig.6 (c) illustrated some graphite agglomeration regions, a better graphite smearing layer was formed than the layer formed in the MMC produced at $800 \mathrm{rpm} 2^{\text {nd }}$ pass Fig. 6 (d), which could affect the wear properties of the produced MMC.

The effect of number of FSP passes on microstructure was studied. Several regions of graphite agglomeration were observed after the FSP $1^{\text {st }}$ pass, Figs. 6(a) and 7(a), but well graphite dispersion regions were found after the FSP $2^{\text {nd }}$ pass, Figs. 6(b) and 7(b). So the dispersion of graphite particles in the AA7075 alloy matrix is enhanced by increasing the number of FSP passes.

AA7075/graphite composite produced at 1200 rpm rotating speed, Fig.7 (a, b) shows lower microstructure homogeneity and higher grain size than the MMC produced at $800 \mathrm{rpm}$ Fig. $6(\mathrm{a}, \mathrm{b})$, this is due to the effect of higher heat input applied to the material during the FSP at $1200 \mathrm{rpm}$ than at $800 \mathrm{rpm}$. 

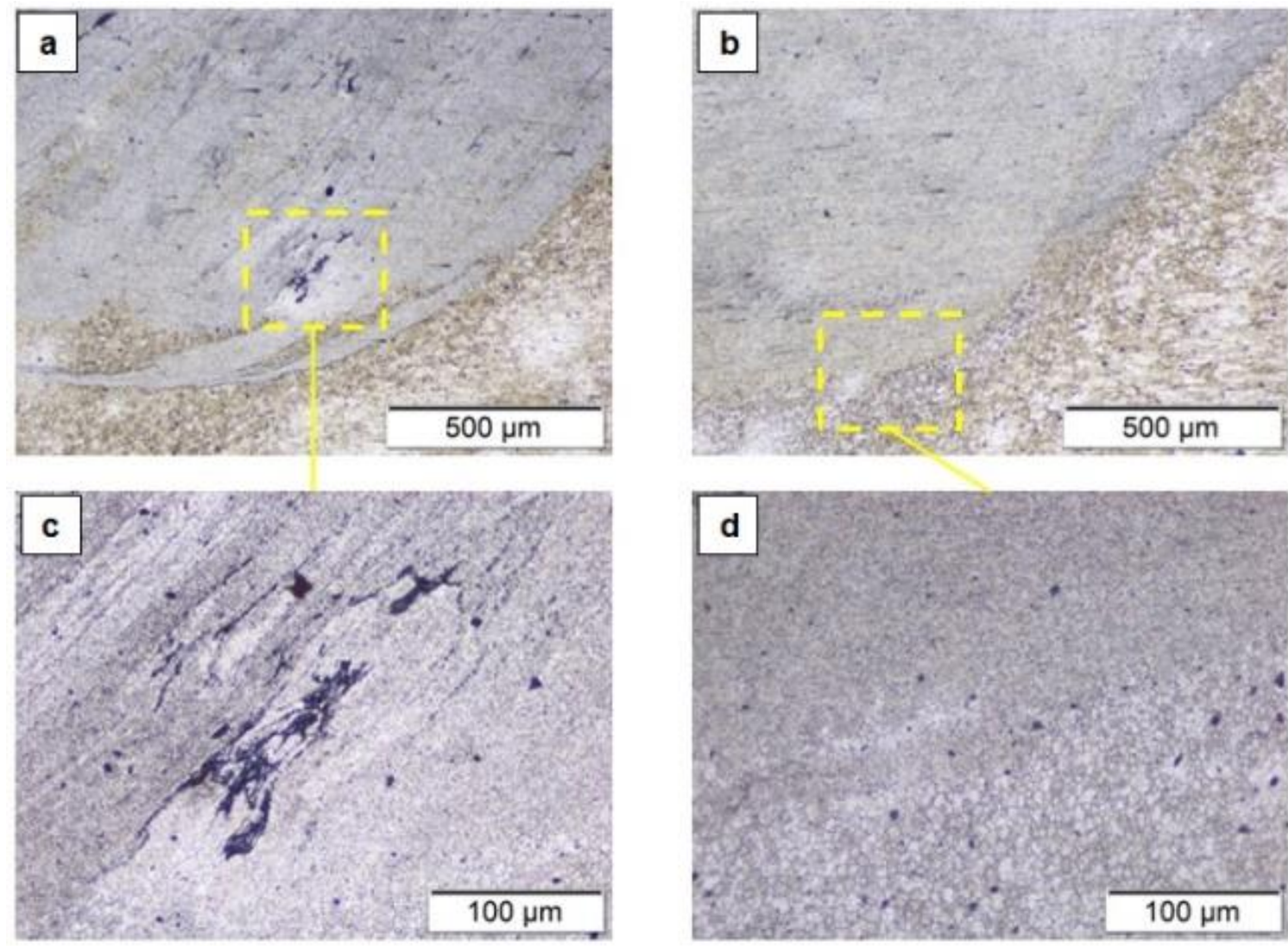

\section{Vickers Hardness}

Fig. 6 (a, c) Microstructure of AA7075/graphite composite at $800 \mathrm{rpm}$ after $1^{\text {st }}$ pass, Fig. 6 (b, d) Microstructure of AA7075/graphite composite at $800 \mathrm{rpm}$ after $2^{\text {nd }}$ pass respectively

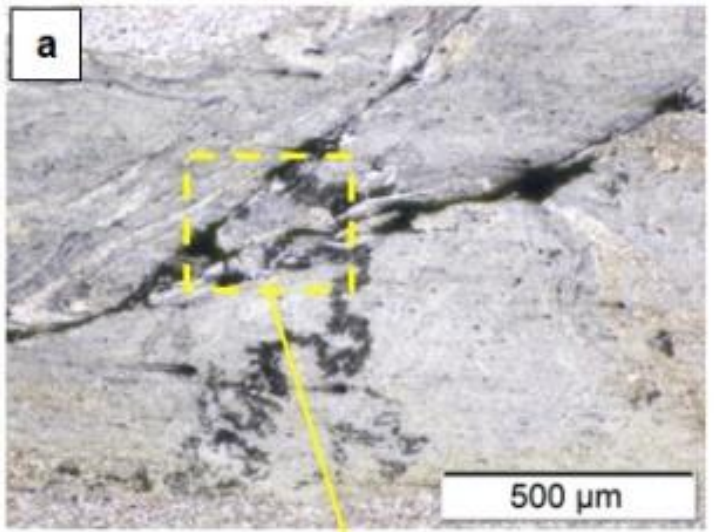

The hardness of AA7075-O base material was 79
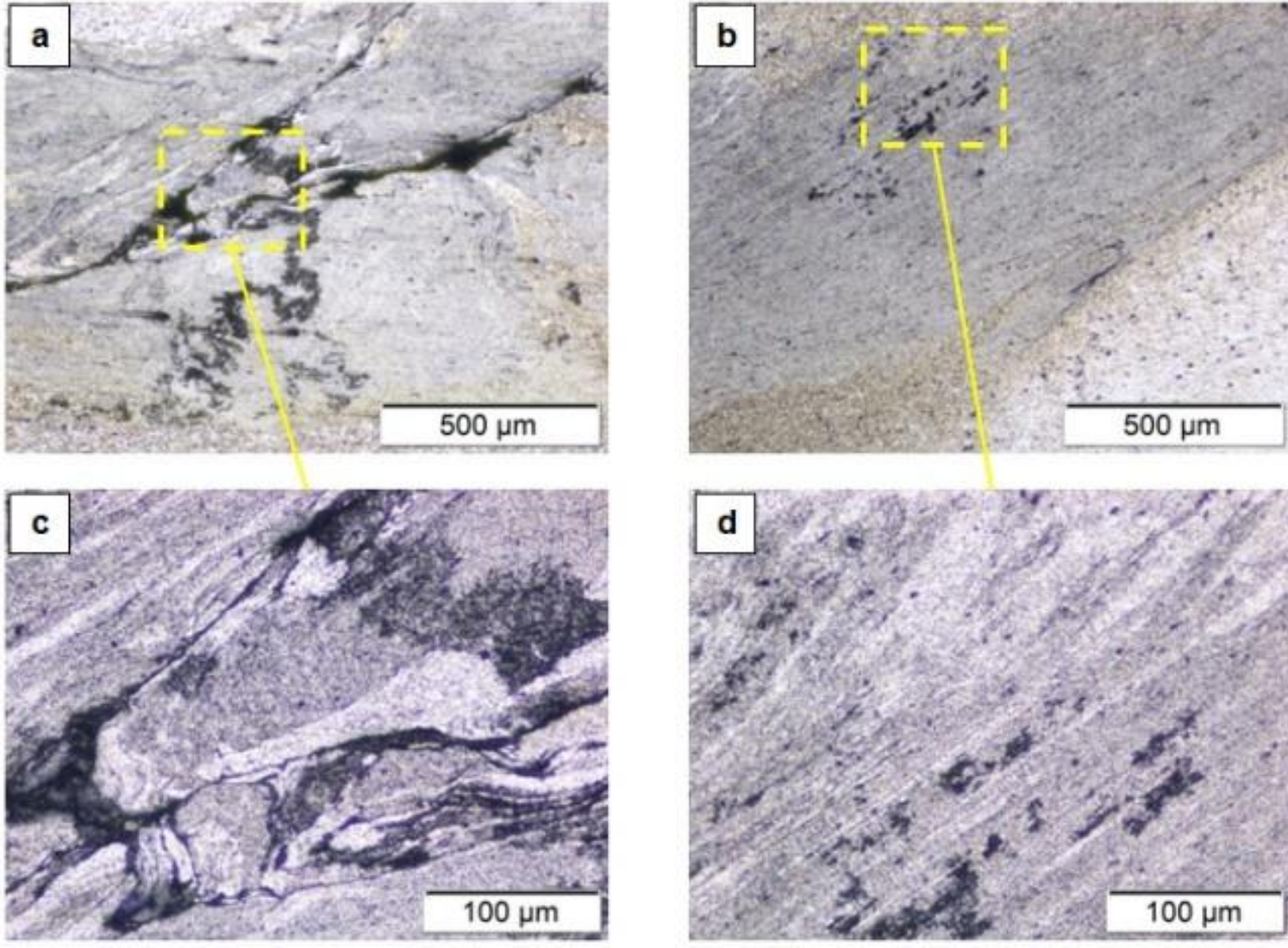

Fig.7 (a, c) Microstructure of AA7075/ graphite composite at $1200 \mathrm{rpm}$ after $1^{\text {st }}$ pass, Fig.7 (b, d) Microstructure of AA7075/ graphite composite at $1200 \mathrm{rpm}$ after $2^{\text {nd }}$ pass respectively

Hv, Fig. 8 shows the average hardness measurements for AA7075 FSPed samples at different rotating 
speeds and different number of passes. It was observed that the average hardness increase with the increasing of FSP rotating speed. This increase in hardness is mainly due to grains refinement.

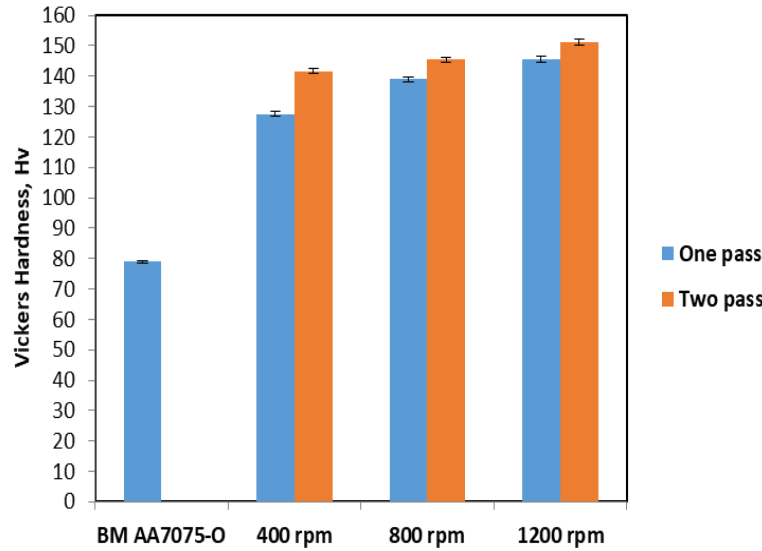

Fig. 8 Average hardness for FSPed samples (without powder) at nugget zone at different rotating speeds, and different number of passes

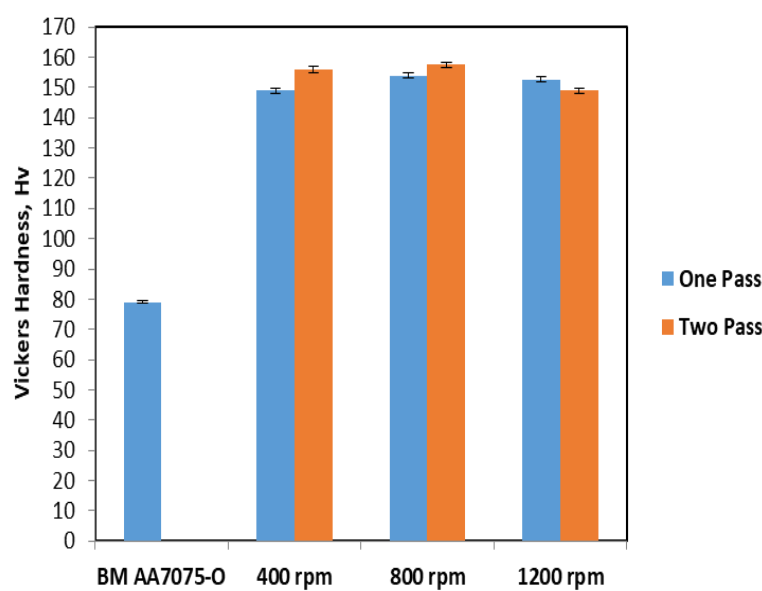

Fig. 9 Average hardness for AA7075/Graphite MMCs at nugget zone at different rotating speeds, and different number of passes

Fig. 9 illustrates that the hardness average values at FSP nugget zone increase with the increasing of FSP rotating speed from 400 to $800 \mathrm{rpm}$, but at $1200 \mathrm{rpm}$ shows different behavior due to the effect of the excess heat input during FSP. It was observed that the average hardness values were increased by adding the graphite powder to the AA7075 metal matrix, as shown in Fig.10.
7075 alloy increasing the material hardness. The graphite particles increase strength as well as decrease the mobility of dislocations in the metal matrix, causing strengthening due to the fine dispersion of particles.

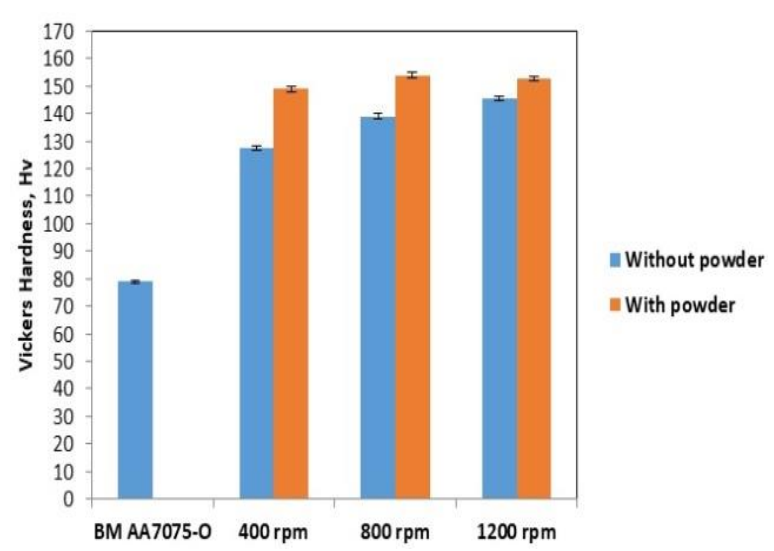

Fig.10 Average hardness for nugget zone at different rotating speeds after FSP $1^{\text {st }}$ pass

A different trend of hardness was reported by Baradeswaran and Elaya [17] where the AA7075/graphite composite was produced by liquid casting technique, the hardness and tensile strength decreased with the increasing in graphite content. Asadi et al. [18] have reported that hardness of the FSPed AZ91/SiC nano composite is observed to be enhanced due to uniform dispersion of SiC particles and refinement of the grain size of the base material. Shamsipur et al. Morisada et al. [19] have published that FSPed nanostructured tool steel exhibited much higher hardness compared to base material. Faraji et al. [20] stated that the increased number of passes FSP in AZ91/Al2O3 nano-composite caused the hardness to become higher- than that of single pass.

\section{Wear characterization}

According to the strong dependence of wear test on the sliding distance and the applied loads, wear test for AA7075-O base metal was conducted at different applied loads $2.45,3.04,3.92$, and $6.37 \mathrm{~N}$ for $10 \mathrm{~min}$ (8920 m sliding distance) to study the wear behavior (weight loss, wear rate, and wear resistance) Fig.11 and Fig.12 of the base metal and choose the suitable applied load for the next wear samples.
The obtained results were compared with the reported ones. A study done by Leyva-Gonza'lez et al. [16] reported that producing AA7075/graphite composite by mechanical alloys and hot extrusion technique, by the addition of graphite particles in the 


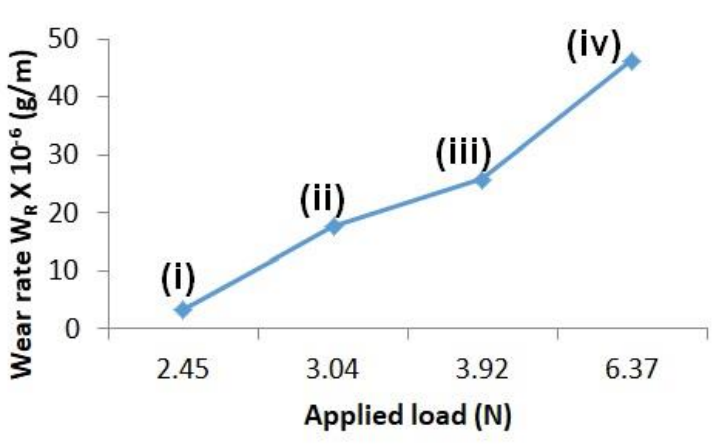

Fig.11 Wear rate behavior of the AA7075-O base metal at different applied loads
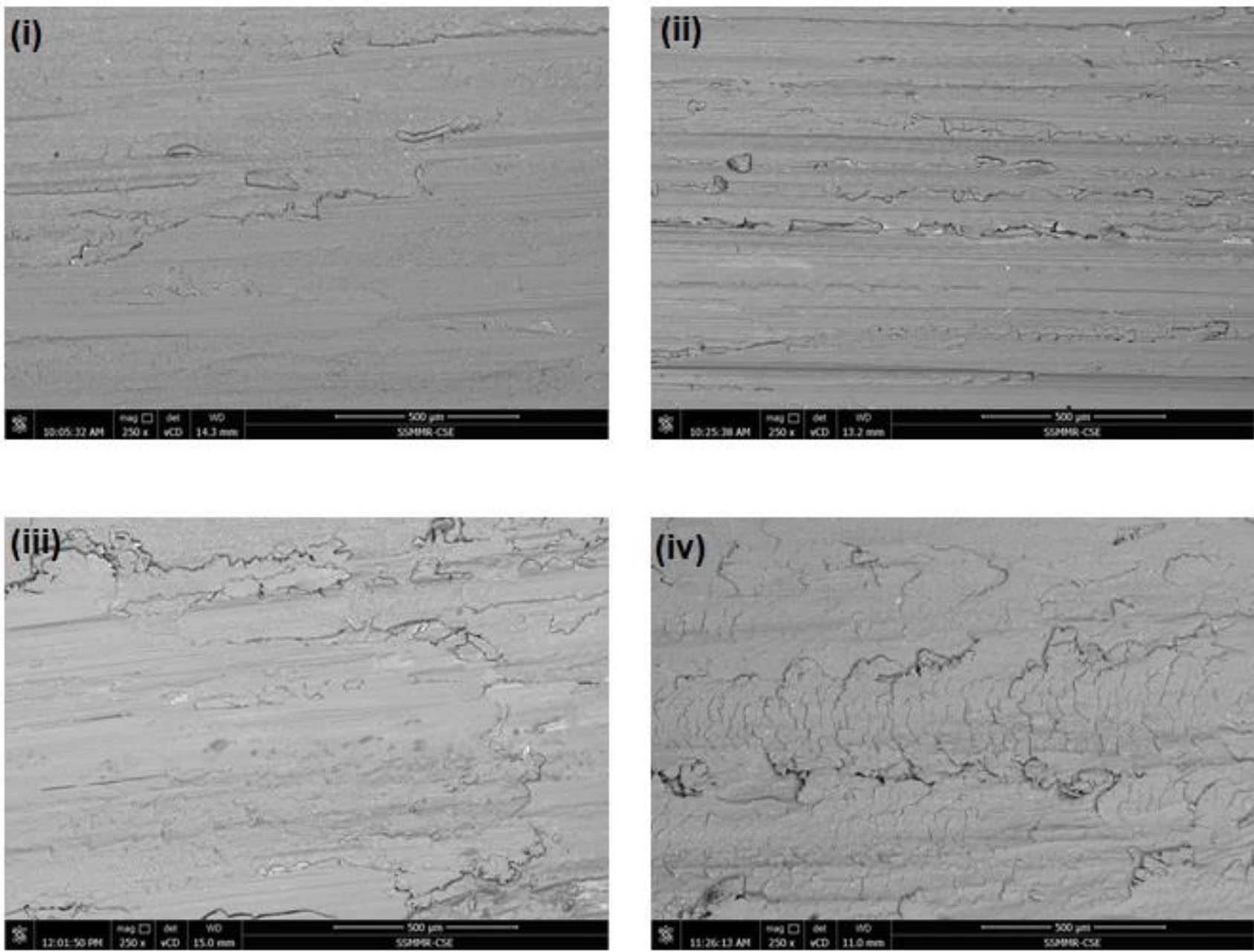

Fig.13 SEM of wear worn surface for the AA7075-O BM at different applied loads

Depending on Fig.11 and Fig.12 the region between 3.04 and $3.43 \mathrm{~N}$ shows a steady state wear rate, so an applied load of $3.04 \mathrm{~N}$ was used to study the wear behavior of the AA7075 FSPed samples and AA7075/graphite composite at different FSP rotating speeds of 400,800 , and $1200 \mathrm{rpm}$, with $50 \mathrm{~mm} / \mathrm{min}$ travel speed for one and two FSP passes. 
Fig.13 shows the SEM wear worn surface track for the AA7075-O BM at different applied load, it was observed that the higher applied load the higher wear debris size.

The effect of FSP rotating speed and number of passes on wear behavior of the produced composites was studied at Fig.14, it was observed that the wear resistance of AA7075-graphite composite increase with increasing FSP rotating speed from 400 to 800 rpm and then decreased with increasing FSP rotating speed up to $1200 \mathrm{rpm}$. This decreasing in wear resistance at $1200 \mathrm{rpm}$ because of the decreasing of material hardness due to the high heat input at this condition Fig. 9.

During study the effect of FSP number of passes on the wear behavior of the AA7075/graphite composite, Fig.14. An unexpected behavior was observed. Where, the AA7075/Graphite MMC graphite composite produced after the FSP $1^{\text {st }}$ pass was show a better wear resistance than the AA7075/ graphite composite after the FSP $2^{\text {nd }}$ pass at both 800 and 1200 rpm FSP rotating speeds.

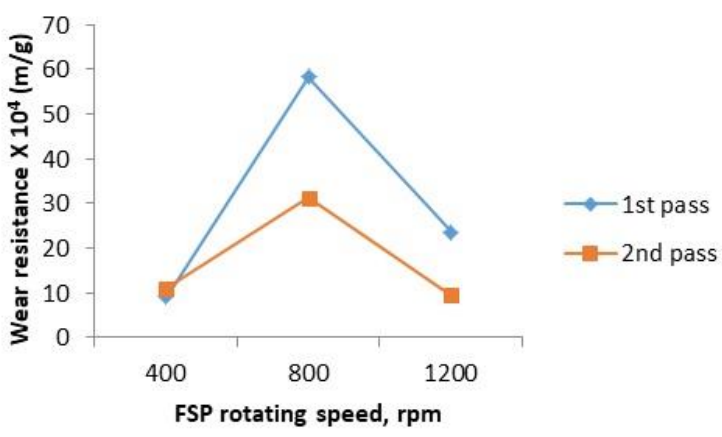

Fig. 14 Wear resistance behavior of AA7075/graphite composite at different FSP rotating speeds, and $50 \mathrm{~mm} / \mathrm{min}$ travel speed

This wear behavior could be explained from the microstructure evaluation of the tested samples. The formation of a better smearing graphite layer at the wear surface of the produced MMC after $1^{\text {st }}$ FSP pass Fig.6(c) and Fig.7(c), enhance the wear behavior for this MMC than the MMC produced after the $2^{\text {nd }}$ FSP pass Fig.6 (d), and Fig.7 (d).

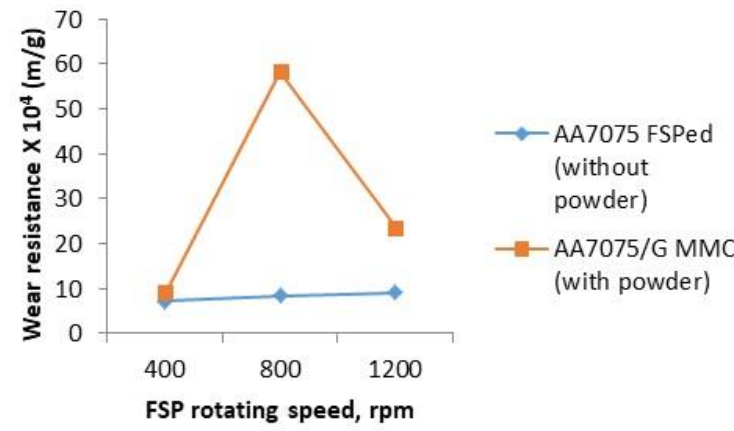

Fig. 15 Wear resistance behavior after the FSP $1^{\text {st }}$ pass, at different FSP rotating speeds, and 50 $\mathrm{mm} / \mathrm{min}$ travel speed

Fig.15 shows the effect of graphite powder addition on the wear resistance behavior of the material at different FSP rotating speeds of 400,800 , and $1200 \mathrm{rpm}$ and constant travel speed of 50 $\mathrm{mm} / \mathrm{min}$. It was observed that the addition of graphite powder leads to increasing the wear resistance of the produced AA7075/graphite composite.

\section{SEM of worn surface}

The SEM of worn surface at FSP rotating speed of 800 rpm after $1^{\text {st }}$ and $2^{\text {nd }}$ pass are shown at Fig.16 (a, b) for the FSPed sample and Fig.16 (c, d) for the AA7075/graphite MMC at the same conditions.

It was observed that the presence of graphite particles Fig.16 (c, d) enhance wear resistance of the produced composite (low debris) than FSPed samples (without powder) Fig.16 (a, b), also the formation graphite smearing layer was observed for the MMC produced at $800 \mathrm{rpm}$ after the $1^{\text {st }}$ pass Fig.16 (c) which enhance the wear resistance than the MMC produced at $800 \mathrm{rpm}$ after the $2^{\text {nd }}$ pass Fig.16 (d). 

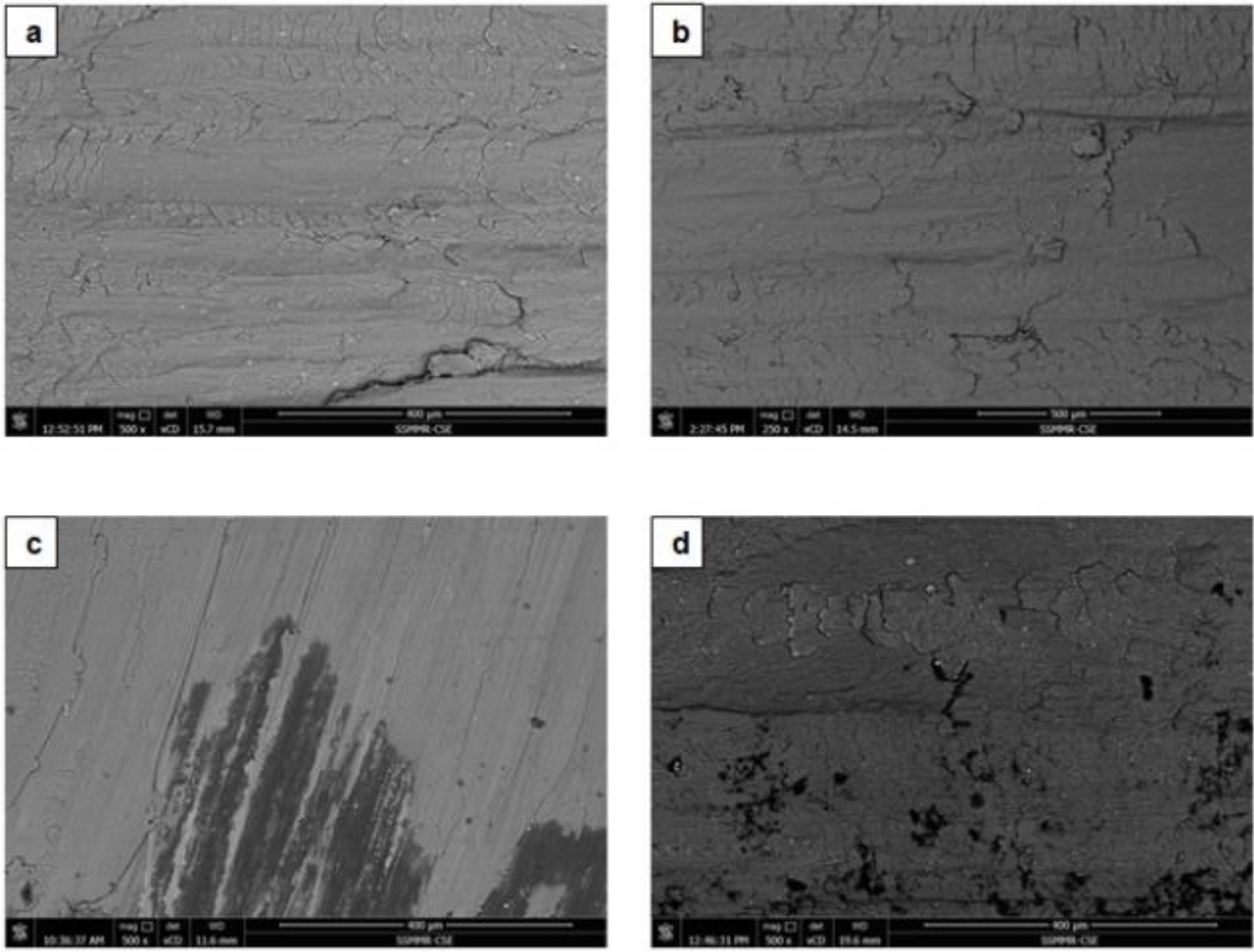

Fig. 16 SEM of worn surface at $800 \mathrm{rpm}$ after the FSP $1^{\text {st }}$ and $2^{\text {nd }}$ pass

\section{Conclusions}

- Sound AA7075/graphite composite was successfully produced using FSP technique by adding graphite powder as a reinforcement material to the AA7075O (annealed) metal matrix. The composite was fabricated by one and two FSP passes, at various FSP rotational speeds $(400,800$, and $1200 \mathrm{rpm})$ with 50 $\mathrm{mm} / \mathrm{min}$ transverse speed.

- Production of AA7075/graphite composite by FSP technique improved the microstructure of the AA7075-O base metal by reforming of a finer and equiaxed grains in the stirring zone (nugget) with a better dispersion of graphite particles.

- The distribution of graphite particles in the stirred zone became more uniform and homogenous by increasing FSP rotating speed and increasing the number of FSP passes due to the repeated stirring action of the tool.

- Increasing of the FSP rotating speed from 400 to 800 rpm has a positive effect on the mechanical properties (hardness and wear resistance) of the produced MMCs, but at 1200 rpm material shows a revers behavior.

- The higher average hardness was reported (156.2 $\mathrm{Hv}$ ) for the AA7075/graphite composite after the FSP $2^{\text {nd }}$ pass at $800 \mathrm{rpm}$ rotating speed with comparing to the AA7075-O base material (79 Hv) and to the AA7075 only FSPed $(145.4 \mathrm{Hv})$ at the same FSP parameters.
- The optimum wear resistance behavior was obtained (58.3 x $104 \mathrm{~m} / \mathrm{g}$ ) from the A7075/graphite composite after the FSP $1^{\text {st }}$ pass at $800 \mathrm{rpm}$ rotating speed with comparing to the AA7075-O base material $(5.7 \times 104 \mathrm{~m} / \mathrm{g})$ and to the AA7075 only FSPed $(8.4 \times 104 \mathrm{~m} / \mathrm{g})$ at the same FSP parameters.

\section{References}

[1] D. Aruri, A. Kumar , B. Kotiveerachary," Tensilel Properties of AA6061-T6/SiC $p$ Surface Metal Matrix Composite Produced By Friction Stir Processing", International Journal of Mechanical and Industrial Engineering , (1) 2011, pp. $26-30$.

[2] Trinh, Son and Sastry, Shankar, "Processing and Properties of Metal Matrix Composites", Mechanical Engineering and Materials Science Independent Study, 10, Washington University, 2016.

[3] Morisada, Fujii, Mizuno, Abe, Nagaoka, Fukusumi, "Nanostructured tool steel fabricated by combination of laser melting and friction stir processing", Mater. Sci. Eng., A 2009, 505, 157-162.

[4] Morisada, Fujii, Nagaoka, Fukusumi, M. "Effect of friction stir processing with $\mathrm{SiC}$ particles on microstructure and hardness of AZ31", Mater. Sci. Eng., A 2006, 433, 50-54. 
[5] Feng, Xiao, Ma, Z.Y. "Effect of microstructural evolution on mechanical properties of friction stir welded AA2009/SiC composite", Compos. Sci. Technol. 2008, 68, 2141-2148.

[6] Wang, Shi, Liu, Li, "A novel way to produce bulk SiCp reinforced aluminum metal matrix composites by friction stir processing", J. Mater. Process. Technol. 2009, 209, 2099-2103.

[7] Shafiei, Kashani, Zarei-Hanzaki, A. "Microstructures and mechanical properties of $\mathrm{Al} / \mathrm{Al}_{2} \mathrm{O}_{3}$ surface nanocomposite layer produced by friction stir processing.Mater", Sci. Eng., A 2009, 500, 84-91.

[8] Cavaliere, "Mechanical properties of Friction Stir Processed 2618/ $/ \mathrm{Al}_{2} \mathrm{O}_{3} / 20_{p}$ metal matrix composite", Composites, Part A 2005, 36, 1657-1665.

[9] Marzoli, Strombeck, Santos, Gambaro, Volpone. "Friction

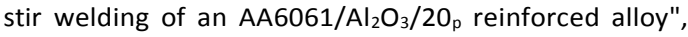
Compos. Sci. Technol. 2006, 66, 363-371.

[10] Surekha, Murty, Prasad, "Effect of processing parameters on the corrosion behaviour of friction stir processed AA 2219 aluminium alloy", Solid State Sciences, vol. 11, no. 4, pp. 907-917, 2009.

[11] Deaquino-L., Estrada-G., Hinojosa-R., Flores-C., HerreraR., Martínez, "Synthesis of aluminum alloy 7075-graphite composites by milling processes and hot extrusion", Journal of Alloys and Compounds 509S (2011) S284S289

[12] Baradeswaran, Elaya P., "Wear and mechanical characteristics of Al 7075/graphite composites", Composites, Part B 56 (2014) 472-476

[13] Sarmadi, Kokabi, Seyed R., "Friction and wear performance of copper graphite surface composites fabricated by friction stir processing (FSP)", Wear 304(2013)1-12.

[14] Mohammed Sh., "Production and characterization of AA7075- $\mathrm{B}_{4} \mathrm{C}$ metal matrix composites using friction stir processing", Suez University, Faculty of Petroleum and Mining Engineering, Department of Metallurgical and Materials Engineering, MSc. Thesis (2018) page 49.

[15] Isadare, Aremo, Adeoye, Olawale, Shittu, "Effect of Heat Treatment on Some Mechanical Properties of 7075 Aluminium Alloy", Materials Research. 2013; 16(1): 190194

[16] Leyva-G., Lara, Pourjafari, Marti', Hernandez-R., GarcıaSa "Calorimetry study of the precipitation in an Al7075graphite composite fabricated by mechanical alloying and hot extrusion", J Therm Anal Calorim (2015) 121:589-595.

[17] Baradeswaran, ElayaPerumal; "Effect of Graphite on Tribological and Mechanical Properties of AA7075 Composites", Tribology Transactions, 58: 1-6, 2015.

[18] Asadi, Givi, Rastgoo, Akbari, Zakeri, Rasouli. "Predicting the grain size and hardness of AZ91/SiC nanocomposite by artificial neural networks", Int J Adv Manuf. Technol, vol. 63, pp.1095-1107, 2012.

[19] Morisada, Fujii, Mizuno, Abe, Nagaoka,. Fukusumi. "Fabrication of nanostructured tool steel layer by combination of laser cladding and friction stir processing", Surf Coat Technol, vol. 205, pp.3397-3403, 2011.
[20] Faraji, Asadi. "Characterization of AZ91/alumina nanocomposite produced by FSP", Mater Sci Eng, vol. 528, pp. 2431-2440, 2011. 